\title{
The Expected Value of Primary English Teachers and Their Strategies
}

\author{
Niu Shu \\ XinJian Primary School, Shanxi, China
}

\begin{abstract}
The value of primary English teacher's expectation is huge and implicit, but it mainly discusses its value from three dimensions of motivation, attitude, and self-confidence in teaching, and makes use of the three functions of motivation, adjustment, and transformation of teacher's expectation, which can effectively inspire primary English teachers to establish feasible teacher's expectation in interaction, use teacher's expectation consciously in teaching, regulate positive teacher's expectation in feedback, and promote students' all-round development.
\end{abstract}

Keywords: primary English, teachers’ expectations, strategies

\section{Teacher Expectations and Teaching Strategies}

In the teaching activities, after the teachers fully understand the students, the resulting teacher expectations affect the prediction and perception of the students' behavior results. And the value of primary English teachers' expectation is to play the role of positive effect to avoid the side effects of negative effect, to establish reasonable expectations to motivate students, in order to transform teacher expectations into self-expectation in operation, to adjust teachers' expectations in time in order to maximize the progress of students' academic level, and to strive to improve teachers' teaching level.

\section{The Value Dimension of Primary English Teachers’ Expectations}

In general, the effectiveness of primary school English teachers' expectation is mainly reflected in the interaction between teachers and students, and it is presented from the aspects of students' motivation, attitude, and self-confidence.

\section{Motivation}

Motivation is the internal motivation or motivation that directly drives the individual to carry out the activity towards a certain goal (Huang, 1997). Learning motivation is the effect of an individual's inner psychological process on learning, not through cognitive construction. The content of learning motivation includes two parts: need and inducement, which have four functions: activation, direction, maintenance, and regulation. The premise of learning motivation is learning needs, which directly motivate students to carry out different learning activities of the internal motivation and drive, and play a positive role in students' learning activities. However, the reason for the student's action is not whether the student has a clear need, but whether there is a stimulus that can meet the needs of the student, that is, the inducement, when the student's learning needs may be further transformed into learning motivation, resulting in the emergence of learning activities.

Niu Shu, B.A., tutor, XinJian Primary School. 
The primary school English teacher is an important inducement in this link, when the students understand the expectation of the primary English teacher, the existing inner state loses its balance, and with the different expectation of the primary English teacher, the students' demands on themselves will be different, especially the auxiliary drive will be stimulated, and the development of the primary school students will depend on the expectation of the primary English teacher, and they will transform it into the motivation of learning for the English teacher's affirmation, reward, and encouragement, and conscious action to realize the teacher's expectation.

For example, “Unit One: How can I Get There?” teaching clip, a multimedia picture showing a school map including canteen, teaching building, library, playground, school hospital, etc. Then, organize and guide the students to practice, such as "How can I get there?” and "Turn left/right at".

$\mathrm{T}$ (Teacher): I came here for the first time, and I want to go to the library, who can help me? (The teacher looks around and the teacher calls a student)

T: I am lost. Can you tell me how can I get to the library? The student hesitated and the teacher gave up after waiting for a few seconds.

T: Ok, sit down please. Who can help me, up your hand?

S: The library is behind the teaching building. Let us go straight and turn left. Follow me. Please.

T: Thank you so much. Good job, sit down please.

It can be seen from the above passage that when the first student does not answer the question, the primary English teacher does not give feedback on the behavior, it can be said that the students cannot understand the idea of the primary English teacher, and the failure of the primary English teacher to give up the students' behavior directly does not help the students to find out the causes of their mistakes, which is not conducive to the correction of the students, or even to a certain extent, it will affect the students' positivity, and even make the students lose the interest and confidence of the subject, which has a long-term and continuous impact on the students.

\section{Attitude}

As the saying goes, "Attitude determines everything”, only the right attitude can form the right behavior. For pupils who have just come into contact with another foreign language, on the one hand, in primary English teaching, strong interest and curiosity are the basis of positive English learning attitude. The need for satisfaction and emotional experience is an important factor affecting the formation of attitudes. Attitude has the elements of emotional experience, and people need to meet the experience has a strong connection. For those who can help them achieve their goals, students will have a positive emotional experience and an optimistic attitude towards them. On the contrary, the object that hinders oneself to achieve the goal or creates frustration to oneself often produces the negative emotion experience to produce the negative attitude. How to maintain students' initial passion and deepen this interest? In primary school, English teaching, reasonable teacher expectation can help students to keep the mentality of vigorous desire for knowledge, teachers should understand students' characteristics in different ways, teach students according to their aptitude, correct students' attitude towards learning English, and correct bad attitude. At the same time, teachers should adopt different teaching methods to convey teachers' positive feelings and expectations, and help students to form and change their positive attitude. For example, "My Schoolbag”, teaches songs to stimulate interest and introduce new lessons. 
Task 1: Song: How many books do you have?

T: We have so many stationaries and books. We love studying. Now, let us sing a song "How Many Books Do You Have?” The students held up their books and began to sing in a warm atmosphere.

The teacher introduced the books in his schoolbag with a small puppet.

T: Hello, boys and girls. I am Puppt. Look, I have a nice schoolbag. I have six books: an English book, a math book, a Chinese book, a notebook, and two story-books (The teacher voiced the puppet in various voices to arouse the interest of the students, introduced the books, and asked the students to remember how many books the puppet had).

T: Boys and girls, how many books does Puppet have? What are they? (The teacher teaches these words again, leads the student to add the study interest to the puppet voice, the student cooperates positively to answer)

In this paragraph, the teacher's introduction teaching has triggered the students' positive learning attitude, which has a good cushion for the later word teaching, and the students can form a dynamic and balanced rhythm with the teachers, which is conducive to the transmission of the expectations of the primary school English teachers.

\section{Self-Confidence}

Self-confidence is a positive attitude towards self-evaluation, believing that you have the ability to accomplish something and affirm the ability you possess. Psychologically, self-confidence is related to Bandura's self-efficacy: the individual's trust in his ability. Strong self-efficacy of the people believe that giving will lead to success, so students will more trust English teachers, under the guidance of teachers, hard to learn English, firmly pay time. But when they are in trouble, weak self-efficacy students will relax or even give up their efforts, so they doubt whether their abilities will lead to the desired success; and those with a strong sense of competence will make greater efforts to overcome the difficulties. Under the positive expectation of the teacher, the students try to act and make efforts. By perceiving the expectations of primary school English teachers, students with different sense of efficacy have different sense of English learning ability, students with strong sense of English learning ability are also more confident in learning English, and have more participation in teaching interaction. They are bold and confident in English class and willing to show themselves. However, the students with weak English skills are always worried that they cannot read well, cannot speak English, do not want to raise their hands to speak, participate in the teaching interaction less, often be on the edge of the English class, and over time, the worse their English performance, the more they feel that they are unable to learn English well, and the lower their English learning efficacy. For example, in "My Family", the teacher plays the animated PPT of the Part Blet's talk section, the whole play, and then the teacher clicks a picture, reads a sentence, and the students try to imitate it in the course of watching. Watch for the second time and encourage students to speak while watching. After listening, guide the students to voice the characters in the courseware group to practice the dialogue for the unit and then perform on stage. In the middle of the performance, we found that the students with strong self-confidence actively participate in the activities, but the students with low self-confidence is the opposite, the students with low self-confidence cannot be well integrated into the classroom activities, resulting in the overall classroom inefficiency. Teachers should pay more attention to students with low self-confidence, give them more opportunities to perform, let all students participate in classroom activities, improve classroom vitality and efficiency, help students solve the difficulties encountered in learning and psychology, thus building self-confidence. 


\section{The Value Function of Primary English Teachers' Expectations}

Teachers have certain expectations of their students, and eventually these students will make progress and positive progress as the teacher expects. This is the function of teachers' expectation, including incentive function, adjustment function, and transformation function.

\section{Incentive Function}

The greatest effect of primary school English teachers' expectations is to motivate students. On the one hand, when students make significant progress in their studies, primary English teachers will give students more attention and encouragement, and students will realize that teachers' expectations are consciously translated into motivation to continue their efforts. Because the primary school students are in the childhood, the psychological development level is not mature, the self-consciousness development level is in the critical period, the formation of the self-concept of the primary school students in this age group will be influenced by their "important others", the recognition degree of primary school English teachers determines the students' evaluation of themselves. On the other hand, the degree of students' trust in teachers and the relationship between teachers and students determine the effect of teachers' expectations on students. If some primary school English teachers are deeply liked by students, students are willing to communicate with teachers, fully trust the authority of teachers, believe in the ability of teachers, then students will be easy to accept the views of teachers and the encouraging information conveyed by teachers; the cornerstone of the transmission of motivation and expectation is a good teacher-student relationship, a harmonious and loving teacher-student relationship helps students to better interact with teachers in class to eliminate students' fear of teachers and English, and to integrate more smoothly into the classroom atmosphere and the rhythm of teaching. It is precisely because the students' positive experience in the classroom makes the students' mental state more optimistic, the teacher's encouragement to the students can make the students feel on schedule, so that the students can integrate the teachers' expectations into the self-expectation, and the direction of the primary school English teachers' expectation is the direction of the students' development, forming a virtuous circle.

The teacher asked the students what they had done over the weekend.

T (Teacher): What did sandy do?

S1 (Student): She helped her mum wash the clothes, tidy the room.

T: So good, what about Bob?

S1: He watched TV.

T: Very good. What about you?

S: I washed the dishes and clothes.

T: Oh, you are a kind and lovely girl, well done, sit done, sit down please (for all students) our parents are very tired every day, we should do something to help them, OK?

S: OK.

After answering the questions, the teachers will continue to guide the students to understand the hard work of their parents, help their parents do what they can, and educate their students on their emotional attitude.

\section{Adjustment Function}

The adjustment function of teachers' expectation is to adjust the relationship between teachers and students and form the "resonance" in cognition and emotion. From the cognitive point of view, trust is the first step to construct the teacher-student relationship. There are no two identical leaves in the world, primary 
English teachers should be aware of the objective differences among students, such as personality type and ability difference, if primary English teachers think that students have high intelligence, strong learning ability, lively and potential, they will give such students high expectations and think that they will achieve good results. Therefore, primary school English teachers should establish a correct view of students, education, and development, comprehensive perspective to view students, to teach students according to their aptitude, to train students to open up and innovate, dare to try, face the difficulties as the basis, believe in the potential of students, and make full use of positive expectations to gain the trust of students. Primary school students are in childhood, self-consciousness is not sound enough, self-evaluation is vulnerable to the influence of "important others", and teachers are its important others. If students are convinced of the authority of English teachers in primary schools, respect for teachers, and teachers are popular with students, then students will actively interact with teachers in the classroom, focus on listening to classes, teaching efficiency is greatly improved, teachers' positive expectations are easily perceived by primary school students, if students ignore teachers, there will be a series of contradictions between teachers and students, the positive effect of teachers' expectations cannot be fully played. First of all, from the cognitive attention, followed by emotion, the communication of teachers' expectations is helpful to the adjustment of the relationship between teachers and students, the practical process of teachers' teaching activities in the classroom, but also the process of emotional communication between teachers and students. "Unit one: Hello! Teaching Fragments", in the vocabulary learning link, after the pronunciation learning, the teacher through the game to strengthen. First, the teacher showed the students the items, such as book, ruler, eraser, pencil, crayon, and pen, and then explained to the students what is missing? The rules of the game (the teacher would randomly hide an item and ask the student to observe and find the lost item) and before the game, the teacher enhanced the word.

T: Show me your pen/book. OK, let us begin. Everybody, look at me carefully. What is missing? (A student stands up to answer)

S: Pencil.

T: Very good, the next one please.

S: Crayon.

T: Well done, sit down please, next one.

S: Ruler. (Wrong answer)

$\mathrm{T}$ : Really? The teacher turned his eyes to the class. I am sorry, she is wrong.

This paragraph is to hinder the healthy development of teacher-student relationship behavior, primary school English teachers to make a wrong response to the activities of students, students' silence, teachers' non-response, so that students have doubts about themselves, lack of courage to try, resistance to teachers, and the correct adjustment of the feelings between teachers and students is that teachers should treat specific problems specifically, but also aim at problems to propose solutions, do not arbitrarily deny and ignore students, should let students feel that teachers pay attention to specific problems, not to individuals, will not have doubts about the relationship between teachers and students, more teachers expect to understand the positive, focus on the problem, both teachers and students to solve problems, but also to adjust the relationship. Through attention and emotion to move and infect students, promote students to actively change, thus forming a harmonious teacher-student relationship.

\section{Transformation Function}

In teaching, primary school English teachers are the leading, students are the main body, and teachers and 
students are individuals with independent personality and dignity. Teaching is based on equality, cooperation, mutual assistance, the expected effect is to create such a situation, trust students, care for students and encourage students; mutual understanding, mutual respect for the construction of a harmonious teacher-student relationship, these key factors determine whether primary English teachers expect to produce the desired results. Because only in a democratic and equal teacher-student relationship, teachers' expectations and love of students to be able to be understood and internalized into a positive emotional experience, need these lively and harmonious atmosphere. Primary English teachers communicate their implicit expected attitudes, expressions, and behaviors to students in a rather subtle way, and are actually more of an unconscious or rather covert behavior. For example, the primary school English teacher points to several students to practice "she" or "he" repeatedly. She is a student, she is a pupil. Playing games, men and women are very different. When the teacher said she, the designated group of female students stood up; when the primary school English teacher said he, the male students stood up. The wrong students quit the game, and after a few rounds, the eliminated students were punished-the two sang an English song. Primary English teachers use "Your voice sound good", "You are a good boy/girl", and "You will be a singer" similar encouraging words to increase student participation. Can let most students participate in the interaction of primary school English teachers to meet the needs of students want to be paid attention to, students in learning to get a positive emotional experience, feel the high expectations of primary school English teachers, the primary school English teachers' teaching goals into their own goals to form their own pursuit.

\section{The Formation Strategy of Primary English Teachers’ Expectation}

As a qualified primary school English teacher, the understanding of teacher expectation strategy affects students' learning life and their own development, mainly through the feasible primary school English teacher expectation in the interaction establishment, in the teaching conscious use primary school English teacher expectation and in the feedback positive primary school English teacher expectation is regulated three kinds of strategies to play a role.

\section{Establish Viable Primary School English Teacher Expectations in Interaction}

First of all, the primary school English teachers' own accomplishment is the premise of the influence on the students. In the actual teaching interaction, many primary school English teachers cannot realize how their behavior is, nor can they pay attention to the relationship between their own behavior and the students' reaction, but only unconsciously play the teacher's expectation. It is shown that the theoretical research of learning teacher's expectation, the discussion of students' meaning, and the importance of teacher's expectation forming factors, and so on influence the expression of primary school English teachers' expectation. Secondly, the primary school English teachers' evaluation of students determines what the primary English teachers expect of the students. Primary English teachers should view and evaluate every student with a developmental and objective view, and believe that the potential of each student is unlimited, if the expectations of the students are relatively low, because of the students' many students, the heavy teaching tasks, the simplification of the information processing process and the influence of the "labeling", the primary English teachers will look at the students with a relatively static view, which is not scientific, we know that the students' condition is not a level of change, especially the pupils' future depends more on the views and treatment of the primary English teachers and others around them, if they can form reasonable and feasible expectations, taking into account 
their ability range and needs, they will learn English better when they achieve another goal. Finally, we should also recognize that teacher expectations are an external reward, and more importantly, combine the needs of students to establish teacher expectations to adapt to the development of students. When setting the relevant expectation goal, the primary English teacher fully combines the "degree" of the student's needs, the "degree" of the student's ability, the student will only have the positive effect to fulfill the expectation within the scope of the ability, and this kind of expectation must be achieved through the students' own efforts to realize one expectation after another, the student will produce the sense of achievement and the self-confidence.

\section{Self-Conscious Use of Primary School English Teacher Expectations in Teaching}

For English teachers in primary schools, the formation of reasonable expectations in feedback is the first step in the formation strategy of English teachers in primary schools. With the in-depth study of the expectations of English teachers in primary schools, English teachers in primary schools are able to apply relevant theories to teaching to better promote the all-round development of students. Learning is the foundation and use is the key. Reasonable expectations are set on the basis of the characteristics of different students, and the role played by English teachers in teaching is different. Primary English teachers need to be alert to their own words and deeds in order to better use. From the previous research, teachers with different styles give students different feelings, compared to a serious, unsmiling teachers, those words are positive, gentle and serious attitude, full of love and understanding of students teachers are deeply welcomed by students, more can be accepted by students. When you ask a question to a student, you will be able to give it a boost to the student. When the student is a little timid about answering the question, he will give it a boost to the student. Sometimes, the speech expression is limited, the psychological quality poor student because of the atmosphere tense, cannot respond to the English teacher's speech quickly in time, this time needs the English teacher to devote the positive attention to the student, with the sincere eye and the smile conveys the English teacher's encouragement and the understanding to him, enables the student to feel the English teacher's non-verbal emotion, then the student will relax naturally. Therefore, English teachers with stable and consistent style can give students positive expectations and consciously use teacher expectations in teaching.

\section{Control Positive Primary School English Teacher Expectations in Feedback}

The last stage of the realization of primary school English teacher's expectation is that after the primary school English teacher conveys the teacher's expectation to the students, with the different information feedback of the students, the original expectation should be adjusted to have an impact on the students. First of all, teachers' expectations need to be timely regulated in the students' "Nearest Development Zone" to suit the positive expectations of each student. "Recent Development Zone" means that there are two levels of student development, one is the level that students already have, the other is the level that can be achieved through the help of others, that is, "jump and pick peaches" (Lin, 2009). For example, in the third paragraph above, the primary school English teacher asked the students to "ruler". The teacher turned his eyes to the class. "I am sorry, she is wrong”. The English teacher only saw that the student's answer to the question was wrong, and only considered the teaching question, but neglected the student's state. At this point, the teachers' expectation exceeds the students' present level, needs the teacher to adjust the expectation according to the students' present condition reduces the expectation or the change strategy, the speech encouragement or the eye smile is also good. It is also a good expectation strategy to suggest another simpler way to inspire students to answer questions that come up. Teachers should be sensitive to their own behavior, but also from the students' 
feedback to determine whether to maintain or adjust expectations. Secondly, the purpose of similar regulation, on the one hand, is to strengthen the students' efforts, English teachers can affirm the students' progress in the interaction, give corresponding expectations to the students, students feel that the improvement of their achievements can be achieved through their own efforts, students realize that they have reached the expectations of English teachers, teachers and students have a tacit understanding of the expected exchange, experience the joy of success, from their own progress has a positive emotional experience, students will change the original negative attitude, enhance confidence, achieve self-worth, and hope to continue to develop. On the other hand, through the feedback of students, self-consciously and skillfully regulate the teachers' expectation, the motivation of students' internal needs stimulated by the teachers' expectation will gradually transform into their own expectation, from "want me to learn" to "I want to learn", students have more autonomy in their own learning, as Jack Bream's theory of confrontation says: "When our free feelings are threatened, we will try to restore it”. Finally, the realization and regulation of primary school English teachers' expectation in the final analysis is for students to be able to learn freely, have full autonomy in their own learning life, and rely on their own efforts to achieve their own pursuit.

\section{Conclusion}

In a word, as a great educational power in teaching, teachers' expectation plays an important role in learning. There is no doubt about the impact of teacher expectations on students, which requires teachers to understand the value of expectations for students' growth and the functionality of expectations for students' learning life. Teaching students according to their aptitude as the right way, teachers should form appropriate expectation strategy according to the characteristics and strengths of students, promote the all-round development of students' physical and mental health, and train students to become independent, confident and responsible people.

\section{References}

Feng, J. Y. (2010). Talk about positive teacher expectation formation strategy. China Science and Education Innovation Guide, (36), 206.

Huang, X. T. (1997). Psychology. Shanghai: Shanghai Education Press.

Li, Y., \& Ma, Y. F. (2018). A study on the influence of teacher expectations on primary school students' learning motivation. Journal of Lanzhou College of Arts and Sciences (Social Sciences Edition), 34(2), 55-58.

Lin, C. D. (2009). Developmental psychology. Beijing: People’s Education Press.

Liu, M. (2017). A study on speech feedback behavior of primary school English teachers. Guangxi: Guangxi Normal University.

Yang, T. Y. (2017). On the positive effects of teachers' expectations on students' development. Heilongjiang Education (Theory and Practice), (4), 35-36.

Zhu, S. (2012). A brief talk on how to give full play to the teacher's expected effect. Science and Education (Chinese Journal), (6), 9-10. 